Syntax Literate: Jurnal Ilmiah Indonesia p-ISSN: 2541-0849

e-ISSN: 2548-1398

Vol. 6, No.7, Juli 2021

\title{
GOODLOOKING INTENTION MILENIAL: BRAINWASHING EFFECT DAN LITERASI JIHAD RENDAH
}

\section{Suhardin, Nurhayati, Ahmad Hunen}

Universitas Ibnu Chaldun (UIC) Jakarta, Universitas Tadulako (UNTAD) Palu, Sekolah Tinggi Agama Islam (STAI) Publisistik Thawalib Jakarta, Indonesia

Email: suhardin@yahoo.com, nurhayatipauduntad@gmail.com, ahmadhunen4@gmail.com

\begin{abstract}
Abstrak
Radikalisme dan terorisme lebih menggambarkan tentang kasuistik, kejadian dan peristiwa yang tengah dialami, penelitian ini lebih menganalisis terkait dengan beberapa variabel yang mempengaruhi goodlooking intention kaum milenial, diantaranya intensitas literasi jihad, intensitas menulis tentang jihad dan pemahaman kaum milenial tentang jihad setelah mengalami brainwashing dalam proses mentoring yang dilakukan murabbi dalam kajian. Tujuan penelitian ini adalah untuk mengkaji keterkaitan antara variabel dengan goodlooking intention, diantaranya intensitas literasi jihad, intensitas menulis berkaitan dengan jihad dan pemahaman terhadap jihad. Penelitian ini menggunakan metode kuantitatif deskriptif liserial yang menggambarkan dan menganalisis pengaruh antar variabel terhadap variabel yang lain, dengan menyasar empat puluh lima jamaah pengajian remaja masjid yang tergolong milenial. Hasil analisis inferensial yang dilakukan ditemukan bahwa brainwashing memiliki effect yang sangat signifikan terhadap goodlookingintention kaum milenial dibandingkan dengan variabel literasi jihad. Ternyata literasi jihad kaum milenial tergolong rendah, karena memang mereka diindoktrinasi harus mendengarkan semua yang disampaikan mentor, murabbi, dan ustadnya. Visi jihad kaum milenial akan dapat dibangun dengan baik dengan cara meningkatkan literasi berkaitan dengan jihad dari berbagai reffrensi standar dan penulis yang otoritatif di bidangnya, sehingga mereka memiliki pencerahan berkaitan dengan visi jihad yang sebenar-benarnya.
\end{abstract}

Kata Kunci: niat goodlooking; milenial; cuci otak; literasi jihad

\section{Abstract}

Radikalisme and terrorism better describe about kasuistik, events and events that are being experienced, this study is more analyzed related to some variables that affect the goodlooking intentions of millennials, including the intensity of jihadi literacy, the intensity of writing about jihad and the understanding of millennials about jihad after brainwashing in the mentoring process conducted murabbi in the study. The purpose of this study is to examine the relationship between variables and goodlookingintentions, including the intensity of jihadi literacy, the intensity of writing related to jihad and understanding of jihad. This study uses a lyserial descriptive quantitative method that describes and analyzes the influence

$\begin{array}{ll}\text { How to cite: } & \text { Suhardin. Nurhayati., Ahmad Hunen (2021) Goodlooking Intention Milenial: Brainwashing Effect dan } \\ & \text { Literasi Jihad Rendah. Syntax Literate: Jurnal Ilmiah Indonesia. 6(7). http://dx.doi.org/10.36418/ } \\ & \text { syntax-literate.v6i7.3625 } \\ \text { E-ISSN: } & \text { 2548-1398 } \\ \text { Published by: } & \text { Ridwan Institute }\end{array}$


between variables on other variables, targeting forty-five mosque youth worshipers who are millennials. Ananalysis ofinferensial found that brainwashing had a very significant effect on the goodlookingintentions of millennials compared to the variables of jihadi literacy. It turns out that the jihadi literacy of millennials is relatively low, because they are indoctrinated to listen to everything delivered by mentors, murabbi, and ustadnya. The vision of jihad of millennials will be well built by improving the literacy related to jihad from various standard reffrensi and authoritative writers in their fields, so that they have enlightenment related to the true vision of jihad.

Keywords: goodlooking intentions; millennials; brainwashing; jihadi literacy

\section{Pendahuluan}

Strategi paham radikal masuk di lingkungan ASN (Aparatur Sipil Negara) dan masyarakat melalui seorang anak goodlooking atau berparas menarik (Razi, 2020). hal ini disampaikan beliau dalam kegiatan Webinar dengan tema Strategi Menangkal Radikalisme pada Aparatur Sipil Negara pada tanggal 5 September 2020 di kantor Kementerian Agama Republik Indonesia. Goodlooking yang dimaksud, merupakan pola yang dilakukan dalam menyebarkan bibit radikalisme ke rumah ibadah. (Razi, 2020) Pernyataan goodlooking menjadi viral di berbagai media sosial dan media mainstream. Pro dan kontra bermunculan di kalangan netizen. Diantarany Irfan Amalee yang menyebutkan bahwa pembahasan mengenai radikalis telah mengalami pergeseran. Stereotipe celana cingkrang, jenggotan, bercadar yang dijadikan justifikasi kelompok tertentu, sekarang mengalami pergeseran ke arah goodlooking (Amalee, 2020). Pengebom di Thamrin itu tampilannya pake jeans, cleanis, rapi berpenampilan menarik dan meyakinkan sebagai seorang anak gaul, tetapi memiliki misi khusus untuk melakukan gerakan radikalis. Hal ini menimbulkan pertanyaan, apa esensialitas dari goodlooking, celana cingkrang tersebut dalam realitas radikalisasi di tengah masyarakat? Mengapa trend ini digandrungi oleh generasi muda milenial? Bagaimana cara yang dilakukan oleh orang untuk membawa para milenialis ke dalam komunitas goodlooking tersebut? Apa yang membuat mereka bersedia dan bergabung dengan sukarela dalam komunitas goodlooking? Bagaimana taktis dan strategis yang dilakukan oleh para pihak yang berwenang untuk menyelesaikan permasalahan tersebut?.

Tahun 2017 Hasnul Harahap meneliti tentang Why Radicalism is growing Among Children (Harahap \& Pemahaman, 2015) beliau meneliti keterlibatan anak dalam perang di Suriah bergabung dengan ISIS, dalam penelitiannya menemukan bahwa anak rentan terpapar dengan radikalisme disebabkan oleh pertama, anak dijadikan target potensialisme rekrutmen jihadis. kedua, anak mudah mengakses konten radikalisme di internet tanpa ada kritisisme. ketiga, ajaran agama dijadikan pendekatan yang lebih meyakinkan dan keempat, pengaruh dan keterpaksaan lingkungan. Muhammad Candra Saputra, meneliti tentang jihad santri milenial melawan gerakan radikalisme di era digital (Syahputra, 2020) dengan menekankan pentingnya kolaborasi santri nusantara untuk berjejaring membangun konten-konten positif dalam bentuk kontra konten 
radikalisme yang disebarkan oleh pihak yang berkepentingan untuk merusak pemahaman generasi milenial. Penelitian (Asrori, 2015) terkait faktor-faktor yang mendorong munculnya radikalisme di Indonesia, menemukan bahwa faktor yang mendorong radikalisme tersebut pertama, perkembangan di tingkat global; kedua, penyebaran paham Wahabisme dan yang ketiga adalah kemiskinan. Terkait dengan fenomena goodlooking (Azca, 2013) dalam penelitiannya terkait dengan kecenderungan anak muda dalam melaksanakan gerakan radikalisme di dorong oleh faktor: pertama, dinamika sosial politik di fase awal transisi menuju demokrasi yang galib ditandai dengan tingginya derajat gejolak dan ketidakpastian;kedua, transformasi gerakan radikal Islam yang sebagian memiliki genealogi pada periode awal kemerdekaan dan ketiga, menjamurnya angka pengangguran di kalangan milenial.

Artikel ini mencoba untuk mengupas tentang kecenderungan milenial dalam berhadapan dengan gerakan radikalisme dalam bentuk goodlookingintention terkait dengan bagaimana paham radikal masuk dalam pemikiran kalangan milenial? Bagaimana gambaran keinginan remaja dalam menjalankan tugas sebagai goodlooking? hubungan antara pemahaman jihad sebagai gerakan radikal, keras, dan hitam putih terhadap keinginan milenial untuk terlibat langsung dalam gerakan jihadis dalam kemasan goodlooking. Variabel yang mempengaruhi goodlooking intention, intensitas literasi jihad, intensitas menulis jihad, pemahaman terhadap jihad yang sudah terbentuk dalam literasi dan brainwashing. Pada penelitian ini mengkaji, menganalisis, membedah dan membandingkan effect dominan dari beberapa variabel independen tersebut kepada variabel terikat yaitu goodlooking intention. Variabel manakah yang dominan mempengaruhi generasi milenial untuk ikut serta dan berperan serta sebagai bagian dari goodlooking.

Radikal dan gerakan radikal di dunia global dan di Indonesia, nyata adanya, bukan isu bukan hoax, tetapi sebuah fakta yang dapat dilihat dan diamati secara fenomenologis. Tentu ia tidak berdiri sendiri dalam sebuah ruang yang kosong, ia berkelit kelindan dengan permasalahan sosial, politik dan budaya yang tengah dialami oleh bangsa Indonesia dan situasi politik internasional. Keterbatasan pengetahuan dan keterbatasan pemahaman terhadap sesuatu objek permasalahan, apakah itu agama, sosial, budaya, politik, ekonomi dan teknologi, membuat seseorang kaku dalam bersikap dan tumpul dalam bertindak. Pengetahuan dangkal dan pemahaman yang sempit menutupi pandangan dan penerawangan pada permasalahan yang lebih luas dan komplek, ia terkubur dan terbelenggu pada pemikiran yang sempit, ruang lingkup yang sumpek, dan ledakan emosional yang tempramental. Hal inilah bentuk nyata dari fenomena sumbu pendek pada kalangan milenial. Ia hanya menerima yang bersifat pengetahuan doktrinal, tidak boleh belajar dengan guru yang lain. Pengetahuan yang diajarkan oleh gurunya mutlak kebenaran, tidak perlu dikonfirmasi dengan guru yang lain. Bacaan yang diterima sesuai dengan kitab yang dianjurkan oleh guru, tidak boleh dikonfirmasi dengan bacaan lain, referensi lain, buku dan kitab yang lain. Segala bentuk pengetahuan, paham, ajaran, informasi yang berbeda dengan yang diajarkan dan kitab yang dibaca, semuanya adalah salah. 
Akar radikal adalah terorisme, ideologi radikal adalah penyebab dari maraknya aksi teror di Indonesia, sehingga pencegahan terorisme harus diikuti oleh pemberantasan radikalisme. (Umar, 2010) Terminologi "radikal" yang membentuk istilah "radikalisme" berasal dari bahasa Latin, radix yang berarti "akar". (Baihaki, 2016) Dengan demikian, "berpikir secara radikal" sama artinya dengan berpikir hingga ke akar-akarnya, hal tersebutlah yang kemudian besar kemungkinan bakal menimbulkan sikap-sikap anti kemapanan. Radikalisme identik dengan perilaku intoleran terhadap perbedaan, ekstrem dalam menyikapi masalah, dan menjadikan kekerasan sebagai cara penyelesaian masalah seperti terorisme. Radikalisme di setiap zaman selalu menjadi common enemy karena selalu menimbulkan berbagai kerusakan di tengah-tengah masyarakat. Radikalisme merupakan sebuah konsep yang bersifat kontekstual dan posisional, dalam hal ini kehadirannya merupakan antitesis dari ortodoks atau arus utama (mainstream), baik bersifat sosial, sekuler, saintifik, maupun keagamaan. Radikalisme tidak mengandung seperangkat gagasan dan argumen, melainkan lebih memuat posisi dan ideologi yang mempersoalkan atau menggugat sesuatu (atau segala sesuatu) yang dianggap mapan, diterima, atau menjadi pandangan umum. (Azca, 2013) dalam hal ini radikalisme adalah paham anti kemapanan, anti kestabilan, anti kekuatan, tetapi berusaha untuk melakukan kajian yang mendalam dan menyeluruh terhadap kompleksitas permasalahan dan berusaha mencari jalan yang lurus dan berusaha untuk merubahnya dengan jalan yang efektif, termasuk di dalamnya juga kekerasan.

Fenomena nyata radikalisme berwujud dalam bentuk teror bom, bom bunuh diri dan agitas kelompok tertentu yang dianggap kafir, berseberangan dengan keyakinan yang dianutnya berdasarkan paham radikal tersebut. Terorisme dalam kaitan ini diartikan sebagai, tindakan kekerasan atau ancaman untuk melakukan tindakan kekerasan yang ditujukan kepada sasaran acak (tidak ada hubungan langsung dengan pelaku) yang berakibat pada kerusakan, kematian, ketakutan, ketidakpastian dan keputusasaan massal. (Mustofa, 2011) Tindakan terorisme tersebut dilakukan dalam rangka memaksakan kehendak kepada pihak yang dianggap lawan oleh kelompok teroris, agar kepentingan-kepentingan mereka diakui dan dihargai. Bom bunuh diri juga semacam serangan yang dilakukan untuk membinasakan musuh dengan meledakkan diri sebagai seorang bomber, hal ini bagian dari jihad. (Mustofa, 2011) Kontek terorisme serangan bom maka dapat menimbulkan perasaan pesimis di kalangan investor terhadap masa depan perusahaan di Indonesia. Investor segera menjual sahamnya sehingga mengakibatkan harga saham akan mengalami penurunan atau terjadi sentimen negatif (Handoko \& Supramono, 2017) aksi terorisme, bom bunuh diri dan beberapa bentuk kekerasan yang dilakukan berujung pada ekonomi, investasi dan penguasaan dalam bentuk geopolitik.

Generasi milenial, potret generasi masa depan yang bersentuhan dengan teknologi digital secara maksimal. Kehidupannya nyaris tidak ada yang terhindar dari fasilitas technology digital. Mereka memiliki relasi dan koneksi global, internasional, mondial, lepas dari belenggu sekat-sekat sosial budaya lokal. Mereka tumbuh besar disaat perkembangan teknologi sedang maju pesat. Menurut (Mutia, 2018) mereka cenderung 
susah dipisahkan dari perangkat teknologi contohnya saja Smartphone. Istilah generasi milenial atau juga disebut sebagai generasi $\mathrm{Y}$ menurut para pakar digolongkan berdasarkan tahun awal dan akhir. Penggolongan generasi milenial atau generasi Y terbentuk bagi mereka yang lahir pada 1980-1990 dan seterusnya. Menurut (Rif'ah, 2019) generasi milenial, sudah menjadi hal yang biasa berbelanja atau bertransaksi tanpa uang tunai. Mereka sudah terbiasa menggunakan alat-alat elektronik seperti kartu debit, kredit, ataupun uang elektronik. Fenomena perubahan gaya transaksi seperti ini dikenal dengan istilah cashless society (masyarakat tanpa uang tunai).

Fenomena milenial yang terlihat di permukaan adalah fenomena hijrah, berpindahnya suatu individu ataupun kelompok ke arah yang lebih baik. Dalam hal ini diartikan sebagai berpindahnya individu ataupun kelompok ke arah yang lebih baik berdasarkan agama Islam. Fenomena hijrah islami menurut (Rif'ah, 2019) banyak terjadi pada masyarakat milenial yang berkembang sangat besar di Indonesia, yang disebabkan oleh adanya keinginan individu atau kelompok untuk menjadi pribadi yang lebih baik lagi dari sisi agama Islam. Hijrah diartikan menjadi makna budaya, individu yang menjauhi diri dari perilaku buruk agar memperoleh gaya hidup yang lebih islami. Keputusan berhijrah terjadi pada kalangan kelas menengah, khususnya mahasiswa karena berpendidikan dan secara ekonomi lebih kaya dibandingkan masyarakat desa, sehingga hijrah terjadi karena sudah populer di media sosial. Para muhajirin milenial berpenampilan menarik dan memikat, cleanis, bersih, rapi dan menarik dalam pembicaraan, dengan tata logika yang sangat kuat dan fasih berdialektika karena berasal dari kalangan akademisi. Mereka berbicara dengan retorika, dialektika yang kuat, logika yang sistematis, runtut, terbangun dalam kerangka konseptual yang rapi dan ilmiah. Mereka tidak bisa menerima hal-hal yang tidak berdasarkan pada materi yang skripturalis, apalagi pendapat dan pandangan ulama yang tidak sehaluan dengan ideologi mereka. Sebaliknya yang berdasarkan pendapat dan pandangan ulama mereka, semuanya diambil sebagai bagian dari kebenaran.

Pola brainwashing yang ditancapkan oleh murabbi, mentor, ustad sangat efektif dalam membangun kerangka konsep dalam otak para milenial yang tergabung dalam goodlooking. Mereka dijajali dengan informasi yang membuat otak generasi milenial mengalami ketakutan, kepanikan, kecemasan, dan keputusasaan terhadap perkembangan global dan situasi politik, ekonomi, budaya bangsa Indonesia pasca reformasi ini. Isu kesenjangan, ketertinggalan, kebodohan, kemiskinan, dan ketidakberdayaan ummat dijadikan santapan untuk membuat milenial mengalami kegalauan dan kepanikan terhadap masa depan. Di tengah kepanikan dan kegalauan tersebut, mereka menawarkan proyek besar pembangunan peradaban baru yang lebih optimistik dan menjanjikan masa depan gemilang generasi baru Islam (Saputra, 2019). Pertama, negara Islam. Kedua, tidak ada riba di dalam negara Islam. Ketiga, negara Islam bebas berdakwah kepada siapa saja. Keempat, kalimat "Ittaqū Allāh" (bertakwalah kepada Allah) sebagai nasihat, bukan vonis ataupun hujatan. Kelima, jika Malaysia dikatakan "truly Asia", maka negara Islam benar-benar global (non-nasionalisme atau 'ashābīyah). Keenam, siapapun yang bertemu di jalan dengan kita, maka dia mengucapkan salam kepada kita dengan 
sebutan ikhwān kepada ikhwān, akhwāt kepada akhwāt. Ketujuh, jangan terkejut bila ada makanan di depan pintu rumah. Kedelapan, tidak ada pergaulan bebas, alkohol, dan pornografi. Kesembilan, semua perempuan berbusana shar' ${ }^{\prime} \overline{1}$. Kesepuluh, kematian bisa datang kapan saja, tetapi semua orang disini "tersenyum". Peradaban yang apik dan sangat menjanjikan bagi kalangan milenial di tengah kerusakan yang terjadi di depan mata, mereka dijanjikan kematian yang tersenyum dengan disambut oleh para penghuni surga.

Membongkar permasalahan kebangsaan dan masa depan umat dalam percaturan internasional jalan lurus yang ditempuh oleh para mentor, murabbi dan ustadz meyakinkan dan merekrut para milenial, seperti diungkapkan (Ma'arif, 2017) bahwa krisis multidimensional berupa gejala kemerosotan moral (akhlak), problematika ekonomi dan pendidikan yang salah, dapat menimbulkan identitas baru seperti tindakan anarkis dan radikalisme agama. Permasalahan sosial budaya, politik dan ekonomi dijadikan pemicu ledakan emosional para milenial, untuk digiring dalam kerangka ideologi yang mereka tanamkan, takfiri, toghut, kekerasan, dan revolusioner, dalam melaksanakan perubahan yang radikal, termasuk di dalamnya rekrutmen dan berbaiat dalam harakah, dengan beradaptasi pada masa dan keadaan yang tengah dialami, termasuk dalam hal ini performance, style, tampilan, tidak harus pakai celana cingkrang, jenggotan, dan jidat hitam, tetapi cleanis, modern, trendy, dan milenialis, inilah potret goodlooking.

Literasi bagian dari internalisasi, capasity building, dan artikulasi diri dalam menangkap berbagai fenomena sosial budaya, dalam makna yang sejati, serta mencoba memformulasikan dalam persepsi, konsepsi dan paradigma. Orang yang membaca akan memiliki perspektif sesuai dengan kerangka konsep yang tengah dia baca, karena literasi bukan hanya kegiatan literasi itu sendiri, tetapi memaknai apa yang dia baca dalam bentuk peta konsep. (Dewey, 2020) Indonesia kata nadiem menduduki posisi 74 dari 79 negara yang diukur tingkat literasinya. Literasi dilakukan dengan kegiatan nyata membaca proposisi dari berbagai kalimat yang terdapat dalam buku bacaan, melakukan pemaknaan, memadukan dalam proposisi sendiri, sehingga terbentuk konstruksi atau kerangka makna dalam konsepsi utuh. Kerangka makna yang sudah diformulasikan dalam posisi yang rapi dikaitkan dengan posisi lainnya sehingga tercipta hubungan dua konsep yang menghasilkan kajian teoritik. Milenialis yang memiliki mentalitas mandiri, memiliki literasi tinggi terutama terkait dengan jihad, ia akan memiliki kerangka paradigma tentang jihad yang sesungguhnya. Tetapi literasi yang dikembangkan di remaja masjid dan pesantren lebih cenderung kepada literasi sebagai media, agency, distribusi paham kekerasan (Malik, Tamjidillah, \& Satriawan, 2020). Budaya literasi pesantren sejatinya menjadi faktor penting yang perlu diteliti terkait dengan penyebaran sel-sel radikalisme dalam tubuh pesantren. Awal stigmatisasi radikal terhadap pendidikan pesantren lebih diakibatkan oleh dua hal, yaitu (1) peran ustaz sebagai figur sentral dalam kultur pesantren (hidden curriculum); dan (2) model literasi atau kurikulum yang diajarkan dalam pesantren tersebut. Demikian juga halnya di kalangan milenial di organisasi remaja masjid. Figur ustad, murabbi, dan mentor menjadi central 
dalam membangun pemahaman terhadap literasi, wacana yang dikembangkan dalam kajian.

Literasi berpengaruh terhadap keinginan (Manurung, Bramani, Ricky, \& Darmanto, 2018) literasi juga berpengaruh terhadap paham, bahkan literasi membangun pemahaman pada kerangka konsep yang dimiliki oleh seseorang. Kerangka konsep dapat membuat seseorang ikut "terlibat" atau "tidak ikut terlibat" dalam melakukan sesuatu, seperti penelitian (Purnomo, 2015) pemahaman siswa terhadap kepedulian lingkungan mempengaruhi keinginan siswa dalam melestarikan lingkungan. Intervening variabel dalam bentuk brainwashing membangun pemahaman, konsep, dan teologi jihadis sangat efektif dalam membangun paham, kerangka konsep, dan kerangka pikir kaum milenialis. Bagaimana peluang litarasi dalam hal ini terutama literasi jihad bagi kalangan milenial, bagaimana tingkat literasinya, penelitian ini berusaha untuk mengungkapkannya secara analisis statistik infrensial.

Artikel ini berangkat dari sebuah penelitian yang bertujuan untuk mengkaji keterkaitan antara variabel dengan goodlooking intention, diantaranya intensitas literasi jihad, intensitas menulis berkaitan dengan jihad dan pemahaman terhadap jihad. Peneliti melihat manakah variabel yang sangat berpengaruh terhadap goodlookingintention di kalangan milenial. Adakah intervening variable yang mempengaruhi? Diantaranya adalah brainwashing ustadz, murabbi mentor yang tengah memberikan paparan kepada para milenial.

\section{Metode Penelitian}

Metode penelitian ini bersifat deskriptif kuantitatif liserial, berusaha mengukur tingkat keinginan goodlooking para milenial yang tergabung dalam organisasi remaja masjid di DKI Jakarta. Samplingnya diambil secara simple random sampling (Nazir, 2005) pada tingkat daerah kota administratif, terpilih Jakarta Timur. Pada Jakarta Timur terpilih beberapa remaja masjid yang berada di kawasan Rawamangun sebanyak empat puluh lima sampling yang dijaring melalui aplikasi google form. (Kamal, 2020) Menemukan responden dan mengisi google form yang disediakan, dalam sebuah etika penelitian kami menjelaskan tentang instrumen dengan sebenar-benarnya dan sebaikbaiknya sekalipun diantara mereka timbul berbagai pertanyaan seputar variabel yang diteliti bermunculan di lapangan, karena ini murni penelitian akademik, sehingga responden tidak berkeberatan untuk mengisinya. Variabel Y (Rahman, 2020) yang diteliti adalah goodlooking intention sedangkan variabel $\mathrm{X}_{3}$ adalah pemahaman jihad, $\mathrm{X}_{2}$ intensitas menulis jihad dan $\mathrm{X}_{1}$ intensitas literasi jihad. Masing-masing variabel telah peneliti kaji secara konseptual sehingga melahirkan definisi konsep dan definisi operasional. (PPs, 2012) Definisi operasional telah dikembangkan menjadi konstruk dan kisi-kisi dan pada akhirnya melahirkan instrumen pengukuran untuk empat variabel tersebut. 


\section{Hasil dan Pembahasan}

Peneliti melakukan pengolahan data deskriptif terkait dengan masing-masing variabel berupa rentang data, Summif data, rerata, deviasi, varians data, dan termasuk juga max dan mint. (Dowdy, Wearden, \& Chilko, 2011) Kemudian mencari normalitas dan homogenitas data pada masing-masing variabel. (Supardi, 2017) Setelah selesai pengolahan deskriptif dan persyaratan analisis data, peneliti melakukan analisis inferensial dengan melakukan analisis jalur dengan menggunakan path analysis. (Retherford \& Choe, 2011) Pada variabel $\mathrm{X}_{1}$ literasi jihad, peneliti mengukur intensitas menulis tentang jihad dengan menyebarkan kuesioner terbuka (Djaali \& Muljono, 2008) dengan menggunakan skala likert 1-4 (Budiaji, 2013) dan telah dilakukan pengolahan komposite skoring, diperoleh data sebagai berikut; jumlah responden=45 rentang data $=60$, cumulative (sum) $=2578$, rerata $=57,30$, std.deviasi $=13,57$, variance $=184,25$, dan median $=51,16$, ode $=50, \max =93$ serta $\min =33$.

Variabel $\mathrm{X}_{2}$ intensitas menulis tentang jihad, peneliti mengukur literasi jihad dengan menyebarkan kuesioner terbuka dengan menggunakan skala likert 1-4 dan telah dilakukan pengolahan komposite skoring, diperoleh data sebagai berikut: jumlah responden $=45$ rentang data $=48$, cumulative $(\mathrm{sum})=1545$, rerata $=34,33$, std.deviasi $=11,37$, variance $=129,47$, dan median $=30,56$, mode $=25$, max $=73$ serta $\min =25$.

Variabel $\mathrm{X}_{3}$ Pemahaman jihad, peneliti mengukur pemahaman jihad dengan menyebarkan kuesioner terbuka dengan menggunakan skala liker 1-4 dan telah dilakukan pengolahan komposite skoring, diperoleh data sebagai berikut; jumlah responden 45 rentang data $=75$, cumulative $(\mathrm{sum})=3188$, rerata $=70,83$, std.deviasi=15,28, variance $=233,58$, dan median $=74,40$, $\operatorname{mode}=75, \max =100$ serta min=25. Pada variabel Y Goodlooking Intention, peneliti mengukur goodlooking intention dengan menyebarkan kuesioner terbuka dengan menggunakan skala likert 1-4 dan telah dilakukan pengolahan komposite skoring, diperoleh data sebagai berikut jumlah responden 45 rentang data $=75$, cumulative (sum) $=2735$, rerata $=60,78$, std.deviasi $=22,66$, variance $=513,58$, dan median $=66,25$, mode $=75, \max =100$ serta $\min =25$.

Perhitungan uji persyaratan analisis berupa uji homogenitas variabel ditemukan bahwa variabel $\mathrm{X}_{1}$ dengan $\mathrm{Y}$ signifikat $=0,241>0,05$ tidak homogen; $\mathrm{X}_{2}$ dengan $\mathrm{Y}$ signifikat $=0,270>0,05$ tidak homogen; $X_{3}$ dengan $Y$ signifikat $=0,00<0,05$ homogen; Uji linieritas $X_{1}$ dengan $Y$ significant $0,142>0,05$ tidak linier. Siginificanty linerity $\mathrm{X}_{2}$ dengan $Y=0,320>0,05$ linier Uji linieritas antara variabel $X_{3}$ dengan $Y$ diperoleh hasil: siginificanty linerity $\mathrm{X}_{3}$ dengan $\mathrm{Y}=0,002<0,05$ linier. Uji normalitas yang digunakan kolmogorov smirnovdiperoleh hasil: variabel $X_{1}$ tidak berdistribusi normal pada sig $=0,069>0,05$, variabel $X_{2}$ berdistribusi normal pada sig $=0,030<0,05$, variabel $X_{3}$ berdistribusi normal pada sig $=0,006<0,05$, dan variabel $\mathrm{Y}$ berdistribusi tidak normal pada sig $=0,438>, 05$.

Setelah menyelesaikan uji persyaratan analisis peneliti mencoba untuk menganalisis pengaruh antara variabel diantaranya pengaruh $\mathrm{X}_{1}$ dengan $\mathrm{Y}, \mathrm{X}_{1}$ dengan 
$\mathrm{X}_{3}$, pengaruh $\mathrm{X}_{3}$ dengan $\mathrm{Y}$, pengaruh $\mathrm{X}_{2}$ dengan $\mathrm{Y}$ dan pengaruh $\mathrm{X}_{2}$ dengan $\mathrm{X}_{3}$ untuk melihat pengaruh antara variabel dalam penelitian liserial.

Tabel 1

Pengaruh antara Variabel dalam Penelitian Liserial

\begin{tabular}{|c|c|c|c|c|c|c|}
\hline \multicolumn{7}{|c|}{ Coefficients $^{a}$} \\
\hline \multirow[t]{2}{*}{ Model } & & Unstandardize & Coefficients & Standardized & $\mathrm{T}$ & Sig. \\
\hline & & B & Std. Error & Beta & & \\
\hline \multirow{2}{*}{1} & (Constant) & 39,731 & 14,616 & & 2,718 & 009 \\
\hline & Membaca & 367 & 248 & 220 & 1,479 & 146 \\
\hline
\end{tabular}

Sumber: Penulis

Digambarkan dalam $\hat{Y}=39,73+0,37 \mathrm{X}_{1}$ terlihat bahwa hubungan $\mathrm{X}_{1}$ dengan $\mathrm{Y}$ adalah bahwa penambahan satu skoring pada $X_{1}$ dalam hal ini literasi jihad akan berpengaruh terhadap $\mathrm{Y}$ dalam hal ini variabel goodlooking intention sebesar 0,37 pada konstanta 39,73. Literasi jihad berpengaruh terhadap goodlooking intention dengan sangat significant yang diperlihatkan oleh sig $=0,009<0,01$, maka pengaruh literasi jihad terhadap goodlooking intention sangat significant. Jika ingin menciptakan remaja yang berkeinginan untuk menjadi mujahid, maka literasi jihadnya dibutuhkan dengan intensif.

Tabel 2

Berpengaruh Literasi Jihad terhadap Goodlooking Intention

\begin{tabular}{|c|c|c|c|c|c|c|}
\hline \multicolumn{7}{|c|}{ Coefficients $^{\mathrm{a}}$} \\
\hline \multirow[t]{2}{*}{ Model } & & Unstandardized & Coefficients & Standardized & $\mathrm{T}$ & Sig. \\
\hline & & B & Std. Error & Beta & & \\
\hline \multirow{2}{*}{1} & (Constant) & 43,889 & 9,181 & & 4,780 & ,000 \\
\hline & Membaca & 470 & 156 & 418 & 3,014 & 004 \\
\hline
\end{tabular}

Sumber: Penulis

Digambarkan dalam $X_{3}=43,89+0,47 X_{1}$ terlihat bahwa hubungan $X_{1}$ dengan $X_{3}$ adalah bahwa penambahan satu skoring pada $X_{1}$ dalam hal ini literasi jihad akan berpengaruh terhadap $X_{3}$ dalam hal ini variabel pemahaman jihad sebesar 0,47 pada konstanta 43,89. Literasi jihad berpengaruh terhadap pemahaman jihad dengan sangat significant yang diperlihatkan oleh $\mathrm{sig}=0,00<0,01$, maka pengaruh literasi jihad terhadap pemahaman jihad sangat significant. Jika ingin menciptakan remaja yang memiliki pemahaman jihad yang benar dan kuat, maka literasi jihadnya dibutuhkan dengan intensif. 
Tabel 3

Pengaruh Pemahaman Jihad terhadap Goodlooking

\begin{tabular}{|c|c|c|c|c|c|c|}
\hline \multirow{2}{*}{\multicolumn{2}{|c|}{ Model }} & \multicolumn{3}{|c|}{ Coefficients $^{a}$} & \multirow{3}{*}{$\mathrm{T}$} & \multirow{3}{*}{ Sig. } \\
\hline & & Unstandardize & Coefficients & Standardized & & \\
\hline & & $\mathrm{B}$ & Std. Error & Beta & & \\
\hline \multirow{2}{*}{1} & (Constant) & 8,155 & 14,174 & & ,575 & ,568 \\
\hline & Pemahaman & ,743 & ,196 & ,501 & 3,796 &, 000 \\
\hline
\end{tabular}

Sumber: Penulis

Digambarkan dalam $\hat{Y}=8,16+0,74 X_{3}$ terlihat bahwa hubungan $X_{3}$ dengan $Y$ adalah bahwa penambahan satu skoring pada $X_{3}$ dalam hal ini pemahaman jihad akan berpengaruh terhadap Y dalam hal ini variabel goodlooking intention sebesar 0,74 pada konstanta 8,15. Pemahaman Jihad berpengaruh terhadap goodlooking intention dengan tidak significant yang diperlihatkan oleh sig $=0,56>0,05$, maka pengaruh pemahaman jihad terhadap goodlooking intention tidak significant. Remaja yang memiliki pemahaman jihad yang benar dan kuat, maka keinginan berjihadnya sangat proporsional pada jihad yang benar sesuai dengan literatur yang dia pahami, ia tidak akan mudah terpengaruh oleh para brainwhoser yang mencuci otak remaja untuk menjadi bomber.

Tabel 4

Pengaruh Intensitas Menulis Jihad terhadap Goodlooking

\begin{tabular}{|c|c|c|c|c|c|c|}
\hline \multicolumn{7}{|c|}{ Coefficients ${ }^{a}$} \\
\hline \multirow{2}{*}{\multicolumn{2}{|c|}{ Model }} & Unstandardize & Coefficients & Standardized & $\mathrm{T}$ & Sig. \\
\hline & & B & Std. Error & Beta & & \\
\hline \multirow{2}{*}{1} & (Constant) & 48,659 & 10,800 & & 4,505 & ,000 \\
\hline & Menulis & ,353 & ,299 & , 177 & 1,181 & ,244 \\
\hline
\end{tabular}

a. DependentVariable: GoodlookingIntention

Sumber: Penulis

Digambarkan dalam $\hat{Y}=48,66+0,35 X_{2}$. terlihat bahwa hubungan $X_{2}$ dengan $Y$ adalah bahwa penambahan satu skoring pada $X_{2}$ dalam hal ini intensitas menulis jihad akan berpengaruh terhadap Y dalam hal ini variabel goodlooking intention sebesar 0,35 pada konstanta 48,65. Intensitas menulis Jihad berpengaruh terhadap goodlooking intention dengan sangat significant yang diperlihatkan oleh sig $=0,00<0,01$, maka pengaruh intensitas menulis jihad terhadap goodlooking intention sangat significant. Remaja yang memiliki intensitas menulis jihad yang tinggi dan banyak, maka kecendrungan goodlooking intention kuat dan tinggi hal ini adalah cara yang dilakukan oleh para brainwhoser untun mempengaruhi para remaja dalam mencuci otak remaja dengan menyuruh menulis paham jihad menurutnya dan memasukkannya dalam otak para remaja, sehingga bersih dan cuci sesuai dengan paham jihad brainwhoser. 


\section{Tabel 5}

Remaja yang Memiliki Intensitas Menulis Jihad yang Tinggi

\begin{tabular}{|c|c|c|c|c|c|c|}
\hline \multicolumn{7}{|c|}{ Coefficients $^{a}$} \\
\hline \multirow[t]{2}{*}{ Model } & & Unstandardizec & Coefficients & Standardized & $\mathrm{T}$ & Sig. \\
\hline & & B & Std. Error & Beta & & \\
\hline \multirow{2}{*}{1} & $($ Constant $)$ & 69,201 & 7,396 & & 9,356 &, 000 \\
\hline & Menulis & ,048 & 205 & 035 & 232 & ,817 \\
\hline
\end{tabular}

Sumber: Penulis

Digambarkan dalam $X_{3}=69,20+0,048 X_{2}$ terlihat bahwa hubungan $X_{2}$ dengan $X_{3}$ adalah bahwa penambahan satu skoring pada $X_{2}$ dalam hal ini intensitas menulis jihad akan berpengaruh terhadap $X_{3}$ dalam hal ini variabel pemahaman jihad sebesar 0,48 pada konstanta 69,20. Intensitas menulis Jihad berpengaruh terhadap pemahaman jihad dengan sangat significant yang diperlihatkan oleh sig $=0,00<0,01$, maka pengaruh Intensitas menulis jihad terhadap pemahaman jihad sangat significant. Remaja yang memiliki intensitas menulis jihad yang tinggi dan banyak, maka pemahaman jihadnya akan kuat dan benar hal ini adalah cara menulis yang perlu diperhatikan, penulisan yang sukarela sesuai dengan literatur yang benar, akan memiliki konsep, paradigma dan pemahaman yang benar, tetapi kalau menulisnya di bawah tekanan dan asuhan seorang mentor, maka paham jihadnya sesuai dengan arahan sang mentor tersebut. Konstalasi hasil phat analysis dapat divisualisasikan sebagai berikut:

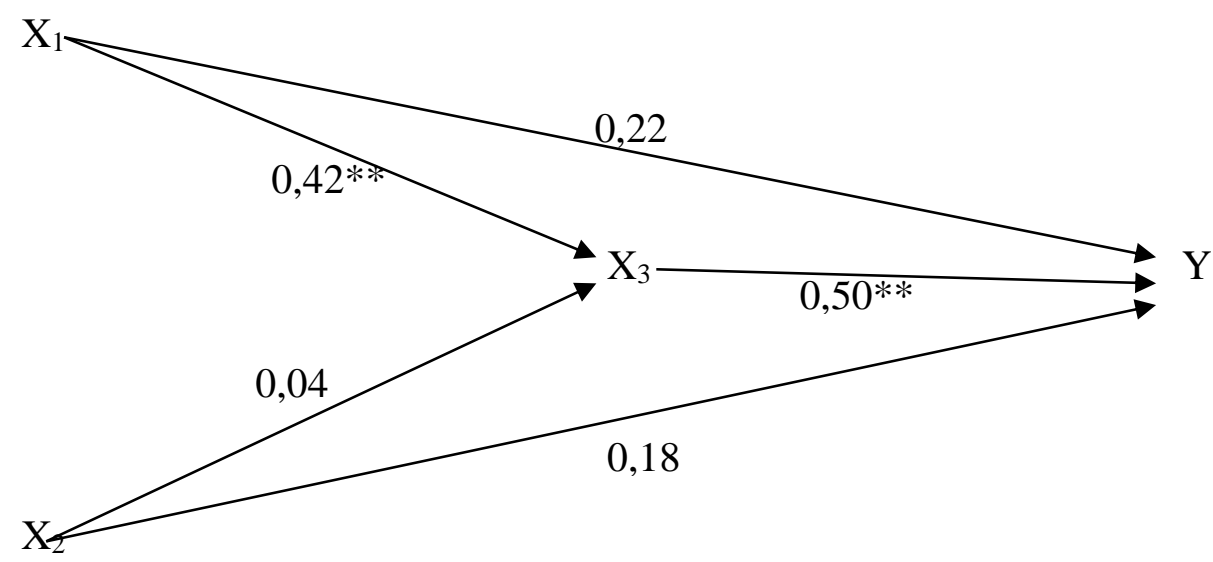

Gambar 1

Koefisien Korelasi

Sumber: Penulis

Gambaran ini memperlihatkan koefisien korelasi antara Literasi Jihad $\left(\mathrm{X}_{1}\right)$ dengan goodlooking intention (Y) sebesar 0,22 dengan hubungan yang tidak signifikant, remaja yang memiliki literasi jihad yang benar, kuat, dan tepat dari reffrensi yang valid dan standar, tidak akan terpengaruh terhadap propaganda dari para brainwhoser, untuk melakukan rekruitment penganten. Literasi jihad $\left(X_{1}\right)$ memiliki koefisien korelasi 
dengan pemahaman jihad $\left(\mathrm{X}_{3}\right)$ dengan indek koefisien korelasi sebesar $0,42 * *$ koefisien korelasinya sangat signifikant, artinya literasi jihad akan membangun konsep, paradigma dan pemahaman jihad sesuai dengan reffrensi dan mentor yang membimbing remaja yang tengah membaca. Jika reffrensinya baik, lurus dan standar maka pemahaman jihadnya akan benar dan lurus, tetapi jika yang mentoringnya memiliki misi tertentu, maka paham jihadnya sesuai dengan misi sang mentoring tersebut. Pemahaman jihad $\left(\mathrm{X}_{3}\right)$ juga memiliki koefisien korelasi dengan goodlooking intention (Y) sebesar $0,50 * *$ dengan sangat signifikan, artinya pemahaman jihad berhubungan dengan goodlooking intention pemahaman jihad yang benar pada seseorang membuat ia akan terjun berjihad secara benar. Seorang remaja yang memiliki paham jihad sesuai dengan tuntunan Islam whashatiyah, Islam moderasi, Islam Nusantara, Islam berkemajuan dan Islam yang tercerahkan, maka jihad yang akan dilakukannya adalah berusaha dengan memaksimalkan kebajikan individual, partisipasi sosial untuk pemberdayaan masyarakat, berusaha semaksimalkan mungkin untuk melakukan al-maunism, berusaha untuk perbaikan lingkungan alam dan ekosistem, agar masyarakat menjadi masyarakat yang berkemajuan dan berkeunggulan, serta menata lingkungan yang equalibrium, berusaha menjadikan umat Islam menjadi umat terbaik yang mengajak manusia ke jalan yang benar dan mencegah kemungkaran. Tetapi apabila paham jihad yang masuk ke dalam otaknya berisikan informasi teror, radikal, perang, maka dengan sendirinya, ia akan terpanggil terjun ke dalam dunia itu.

Intensitas menulis tentang jihad $\left(\mathrm{X}_{2}\right)$ berhubungan dengan goodlooking intention (Y) dengan koefisien korelasi sebesar 0,18 dengan tdak signifikan demikian juga halnya dengan pemahaman jihad $\left(\mathrm{X}_{3}\right)$ koefisien korelasi sebesar 0,04 dengan tidak signifikan. Intensitas menulis dapat memberikan dorongan kepada seseorang untuk melakukan hal-hal yang ia pikirkan dan tuangkan dalam tulisannya. Para pergerakan keislaman dan keindinesian pada umumnya para tokoh yang menulis. Tulisannya mempengaruhi dirinya dan orang lain untuk melakukan hal-hal yang diisukan dalam tulisan tersebut. Tetapi dalam hal ini para remaja memiliki nilai intensitas menulis rendah, sehingga konstribusinya dalam pemahaman dan keinginan berjihad yang bernar, tepat dan sesuai tuntunan rendah. Menulis yang dilakukan remaja yang terpapar dalam treatment para brainwhoser, sesuai dengan paham, dan doktrin yang ditanamkan secara kuat dalam otak para remaja yang ditarget mereka. Tulisan yang dibuat, mengarahkan remaja memiliki pemahaman jihad sesuai dengan paham mentornya, untuk menjadikan remaja sebagai bagian dari goodlooking intention.

\section{Kesimpulan}

Hasil temuan penelitian terlihat, bahwa pengaruh literasi jihad terhadap goodlooking intention tidak signifikan dan memiliki pengaruh rendah 0,22 dengan determinasi $04,84 \%$, keinginan kaum milenial terlibat dalam gerakan goodlooking hanya dipengaruhi oleh literasi jihad sebesar 04,84\% sangat kecil. Kaum milenial sangat terlihat dalam data memiliki intensitas rendah dalam melakukan literasi jihad hanya berkisar pada angka rata-rata=57,30, median=51,16, dan mode mode $=50$, pada 
umumnya berada di bawah rata-rata, hanya sebagian kecil yang di atas rata-rata, hal ini memperlihatkan bahwa literasi jihad dikalangan milenial tidak menjadi budaya yang kondusif. Bacaan yang diberikan kepada mereka pada umumnya bacaan yang sudah di persiapkan oleh mentoringnya, sehingga ia berkorelasi signifikan dengan kerangka berpikir dan pemahaman terhadap definisi, pengertian, dan paradigma jihad dalam pikiran mentoring tersebut, hal ini dibuktikan dengan koefisien korelasi yang sangat signifikan sebesar 0,42 dengan koefisien determinasi 17,47\% artinya pemahaman jihad yang melekat dalam otak para milenial dipengaruhi oleh bahan bacaan yang diberikan mentoring untuk brainwashing (cuci otak) sebesar 17,47\% dan hal ini berpengaruh kepada goodlooking intention sebesar $25,10 \%$ persen. Hubungan pemahaman jihad dengan keinginan bergabung dengan gerakan (goodlooking intention) sangat signifikan pada koefisien korelasi 0,50. Goodlooking intention dipengaruhi oleh pemahaman jihad yang sudah dibangun oleh mentoring melalui kegiatan brainwashing.

Temuan tersebut dapat disimpulkan bahwa literasi jihad remaja rendah, sehingga mudah dirasuki oleh pemahaman jihad yang keliru dari berbagai media, terutama yang disuguhi oleh gerakan tertentu menjadikan remaja sebagai target goodlooking yang di tugaskan menjadi guidence, movement, dan langsung menjadi penganten. Temuan dan kesimpulan yang didapat pada penelitian ini, peneliti menyarankan kepada Kementerian Agama Republik Indonesia untuk banyak berperan dalam memberikan pemahaman keagamaan masyarakat yang benar dengan mengoptimalkan kegiatan penyuluh keagamaan yang ada pada Kantor Urusan Agama di Kelurahan. Kepada organisasi kemasyarakatan Islam, Majelis Ulama Indonesia, lebih kuat lagi memberikan pemahaman washatiyatul Islam, Islam Moderasi, Islam Berkemajuan, Islam Nusantara, agar pemahaman keberagamaan masyarakat benar-benar tergali dari sumber ashlynya dengan manhaj yang tepat, benar, akurat dan berdasar. Agar remaja terhindar dari impor pemahaman yang keliru tentang agama dan keagamaannya, dirasuki oleh pemahaman terkait dengan permasalahan sosial dan politik kebangsaan, membuat remaja bersedia ikut bergabung dalam gerakan jihadis yang keliru. 


\section{BIBLIOGRAFI}

Amalee. (2020). Pernyataan Menag Dikhawatirkan Memunculkan Stereotip Baru Bagi Orang-Orang Goodlooking. Retrieved From Tribun News Website: Https://Www.Tribunnews.Com/Nasional/2020/09/06/Pernyataan-MenagDikhawatirkan-Munculkan-Stereotip-Baru-Bagi-Orang-Orang-Good-Looking. Tribun News, 2. Google Scholar

Asrori, Ahmad. (2015). Radikalisme Di Indonesia: Antara Historisitas Dan Antropisitas. Kalam, 9(2), 253-268. Google Scholar

Azca, Muhammad Najib. (2013). Yang Muda, Yang Radikal: Refleksi Sosiologis Terhadap Fenomena Radikalisme Kaum Muda Muslim Di Indonesia Pasca Orde Baru. Jurnal Maarif, 8(1), 14-44. Google Scholar

Baihaki, Egi Sukma. (2016). Interpretasi Al-Qur'an-Hadis Terhadap Munculnya Gerakan Kaum Jihadis. Farabi, 13(2), 293-307. Google Scholar

Budiaji, Weksi. (2013). Skala Pengukuran Dan Jumlah Respon Skala Likert. Jurnal Ilmu Pertanian Dan Perikanan, 2(2), 127-133. Google Scholar

Dewey, J. (2020). Konsep "Merdeka Belajar" Perspektif Aliran Progresivisme. Jurnal Studi Guru Dan Pembelajaran, 3(1), 141-147. Google Scholar

Djaali, Pudji Mulyono, \& Muljono, Pudji. (2008). Pengukuran Dalam Bidang Pendidikan. Jakarta: Grasindo. Google Scholar

Dowdy, Shirley, Wearden, Stanley, \& Chilko, Daniel. (2011). Statistics For Research (Vol. 512). Virginia: John Wiley \& Sons. Google Scholar

Handoko, Wina Meilia Waspadiana, \& Supramono, Supramono. (2017). Sentimen Investor Terhadap Peristiwa Terorisme Berbasis Fundamental Perusahaan (Studi Pada Peristiwa Serangan Bom Sarinah 14 Januari 2016). Jurnal Akuntansi Dan Keuangan, 19(2), 122-132. Google Scholar

Harahap, Sumper Mulia, \& Pemahaman, Studi Terhadap. (2015). Keyakinan, Dan Praktik Keberagamaan Masyarakat Batak Angkola Di Padangsidimpuan Perspektif Antropologi. Jurnal Toleransi: Media Komunikasi Umat Bergama, Uin Suska Riau, 7(2), 1-23. Google Scholar

Kamal, Irsyad. (2020). Pembelajaran Di Era 4.0 Aplikasi Teknologi Informasi Dalam Pembelajaran. Bandung: Penerbit Yrama Widya. Google Scholar

Ma'arif, Safi'i. (2017). Syafii Maarif: Negara Tidak Boleh Kalah Oleh Penganut 'Teologi Maut. Retrieved From Kompas Website: Https://Nasional.Kompas.Com/Read/2017/04/08/1. Google Scholar

Malik, Abdul, Tamjidillah, Tamjidillah, \& Satriawan, Satriawan. (2020). Budaya 
Literasi Dan Infiltrasi Gerakan Islam Radikal Di Pesantren Indonesia. Islamica: Jurnal Studi Keislaman, 15(1), 48-67. Google Scholar

Manurung, Hakim, Bramani, Resi, Ricky, Immanuel, \& Darmanto, Darmanto. (2018). Pengaruh Literasi Keuangan Terhadap Intensi Berinvestasi Dengan Moderasi Self Regulatory Focus. Indonesian Business Review, 1(1), 51-60. Google Scholar

Mustofa, Imam. (2011). Bom Bunuh Diri: Antara Jihad Dan Teror. Al-Manahij: Jurnal Kajian Hukum Islam, 5(1), 109-124. Google Scholar

Mutia, Tika. (2018). Generasi Milenial, Instagram Dan Dramaturgi: Suatu Fenomena Dalam Pengelolaan Kesan Ditinjau Dari Perspektif Komunikasi Islam. An-Nida', 41(2), 240-251. Google Scholar

Nazir, Moh. (2005). Metode Penelitian, Ghalia Indonesia. Jakarta: Nuraini R, Eka. Google Scholar

Pps, U. N. M. (2012). Pedoman Penulisan Tesis Dan Disertasi Program Pascasarjana Unm Makassar. Makassar: Pps Unm. Google Scholar

Purnomo, Agus. (2015). Pengaruh Pembelajaran Outdoor Terhadap Pengetahuan, Dan Sikap Pelestarian Lingkungan Mahasiswa S1 Pendidikan Geografi Universitas Kanjuruhan Malang. Jurnal Pendidikan Geografi: Kajian, Teori, Dan Praktek Dalam Bidang Pendidikan Dan Ilmu Geografi, 20(1), 37-47. Google Scholar

Rahman, Inayah. (2020). Pola Pengelolaan Wakaf Produktif Sektor Pertanian (Studi Kasus Pimpinan Ranting Muhammadiyah Penatarsewu). Fakultas Ekonomi dan Bisnis. Universitas Airlangga. Google Scholar

Razi, Fachrul. (2020). Pernyataan Agen Radikalisme Goodlooking Berbuntut Panjang. Retrieved From Detik.Com Website: Https://News.Detik.Com/Berita/D5160479/Pernyataan-Menag-Agen-Radikalisme-Good-Looking-BerbuntutPanjang. Detik.Com, 2. Google Scholar

Retherford, Robert D., \& Choe, Minja Kim. (2011). Statistical Models For Causal Analysis. Hawaii: John Wiley \& Sons. Google Scholar

Rif'ah, Sifwatir. (2019). Fenomena Cashless Society Di Era Milenial Dalam Perspektif Islam. Al-Musthofa: Journal Of Sharia Economics, 2(1), 1-14. Google Scholar

Saputra, Eko. (2019). Menelisik Dinamika Radikalisme Gen Z Perempuan Di Facebook. Islamica: Jurnal Studi Keislaman, 14(1), 103-125. Google Scholar

Supardi. (2017). Statistik Penelitian Pendidikan Perhitungan, Penyajian, Penjelasan, Penafsiran, Dan Penarikan Kesimpulan (Ke-1). Diakses dari http://repository.uinbanten.ac.id/3722/8/dapus.pdf. Google Scholar

Syahputra, Muhammad Candra. (2020). Jihad Santri Millennial Melawan Radikalisme 
Suhardin, Nurhayati, Ahmad Hunen

Di Era Digital: Studi Gerakan Arus Informasi Santri Nusantara Di Media Sosial. Jurnal Islam Nusantara, 4(1), 69-80. Google Scholar

Umar, Ahmad Rizky Mardhatillah. (2010). Melacak Akar Radikalisme Islam Di Indonesia. Jurnal Ilmu Sosial Dan Ilmu Politik, 14(2), 169-186. Google Scholar

\section{Copyright holder:}

Suhardin, Nurhayati, Ahmad Hunen (2021)

First publication right:

Syntax Literate: Jurnal Ilmiah Indonesia

This article is licensed under:

(c) (i) (? 